\title{
Atividade inibidora de bactérias lácticas, em embutidos de carne curados
}

\section{Antimicrobial activity of lactic acid bacteria isolated from Brazilian fermented sausage}

\author{
Celso Rodrigues de Carvalho', Wagner Luiz Moreira dos Santos ${ }^{1}$ Cristiano Sales Prado', Elvio Carlos Moreira², \\ José Oswaldo Costa ${ }^{2}$
}

\section{Resumo}

A atividade antimicrobiana de 336 bactérias lácticas isoladas de linguiças artesanais de Santa Luzia, Estado de Minas Gerais, foi avaliada frente a diversos microrganismos indicadores de interesse para a industria alimentícia. Essas bactérias foram submetidas ao teste da atividade antimicrobiana direta que identificou as produtoras de substâncias antagonistas capazes de inibir in vitro o desenvolvimento de duas cepas de Staphylococcus aureus. As 98 cepas que inibiram, por esta prova, pelo menos um desses microrganismos, receberam a denominação DTEl e foram selecionadas para o teste de inibição indireta, sob condições que neutralizassem o efeito inibidor dos ácidos orgânicos e peróxido de hidrogênio, contra as mesmas cepas de $S$. aureus contra algumas bactérias lácticas de diversas origens e contra uma cepa de Listeria monocytogenes. Os resultados demonstraram que as bactérias lácticas isoladas das linguiças artesanais de Santa Luzia, não manifestaram atividade antagonista indireta frente a qualquer das cepas de $S$. aureus utilizadas no presente trabalho. Contudo, três cepas ofereceram resultados positivos na atividade inibitória indireta frente a alguns microrganismos taxonomicamente relacionados, sugerindo terem produzido substâncias antimicrobianas no meio de cultivo. As cepas isoladas foram caracterizadas bioquimicamente $e$ identificadas como Lactobacillus sp.

Palavras chave: bactérias lácticas; atividade antimicrobiana; embutidos cárneos; Staphylococcus

\section{Introdução}

Os alimentos de origem animal são bastante susceptíveis às contaminações bacterianas e estão sujeitos a sofrerem transformações diversas em decorrência da ação de microrganismos adulterantes. Além disso, os alimentos de origem animal podem ser responsáveis pela veiculação de diversos microrganismos patogênicos ao homem. Por isso, surgiram vários métodos de conservação que visam principalmente o aumento do prazo de vida comercial dos alimentos e a obtenção de produtos seguros à saúde humana. Dentre esses, a fermentação, geralmente associada à secagem, é um dos métodos mais antigos que se conhece, prevenindo alterações e aumentando a estabilidade dos produtos em climas quentes, além de conferir aos alimentos características organolépticas e nutricionais desejáveis (Yamada e Beraquet, 1993; Holzapfel et al., 1995).

O processo fermentativo é exercido por um grupo de microrganismos conhecidos, genericamente, como bactérias lácticas, devido à capacidade que possuem de utilizar os carboidratos disponíveis no substrato, formando diversos ácidos orgânicos, principalmente o ácido láctico (Stamer, 1979). Além disso, sabe-se que elas produzem outras substâncias antimicrobianas (Daeschel et al., 1989; Piard e Desmazeaud, 1991, 1992), sendo as bacteriocinas consideradas as mais interessantes tecnologicamente, pois, devidoà sua natureza proteica (Tagg et al., 1976; Schillinger et al., 1993; Jack et al.,1995), podem ser inativadas pelas enzimas do trato gastrointestinal, além de serem atóxicas e não possuirem propriedades imunogênicas nos animais de experimento (Bhunia et al.,' 1990).

As bactérias lácticas isoladas da carne, ou de seus derivados, são provavelmente as mais eficazes para assegurar a qualidade microbiológica desses produtos por estarem melhor adaptadas a esses substratos. Assim, se evidencia que o isolamento de bactérias lácticas de origem cárnea produtoras de bacteriocinas, é condição indispensável para se utilizar seu potencial como fator de segurança no controle da qualidade higiênico-sanitária da carne e derivados. $O$ isolamento e a identificação de bactérias lácticas de embutidos que manifestem atividade antimicrobiana frente a cepas de Staphilococcus aureus e a avaliação da atividade inibitória dessas bactérias frente a alguns microrganismos de várias origens foram os principais objetivos deste trabalho.

\footnotetext{
Trabalho financiado CNPq - Processo 520 950/95-0

1 Departamento de Tecnologia e Inspeção de Produtos de Origem Animal, Escola de Veterinária, Universidade Federal de Minas Gerais, UFMG, Belo Horizonte, MG, Brasil

2 Departamento de Medicina Veterinária Preventiva,Escola de Veterinária, UFMG
} 


\section{Material e Métodos}

No período de março e abril de 1995, foram adquiridas aleatoriamente no Mercado Central da cidade de Belo Horizonte, Estado de Minas Gerais (MG), sete amostras de linguiça caseira provenientes de Santa Luzia, MG, que foram transportadas para o Laboratório de Bactérias Lácticas do DTIPOA, da Escola de Veterinária da UFMG, onde foram processadas.

Foram colhidos $20 \mathrm{~g}$ da porção central da amostra e homogeneizados com $180 \mathrm{ml}$ de meio de enriquecimento composto por água peptonada a $1 \% \operatorname{com~} 0,85 \%$ de $\mathrm{NaCl}$. Em seguida, o homogeneizado foi incubado em estufa a $35^{\circ} \mathrm{C} / 4 \mathrm{~h}$. A seguir, foram obtidas diluições subseqüentes até as concentrações de $10^{-6}$. De cada uma das diluições, tomaram-se alíquotas de $100 \mu$ l que foram semeadas em sistema de dupla camada de MRS-ágar 1,5\% e incubadas a $35^{\circ} \mathrm{C}$ por $48 \mathrm{~h}$. Após este período, as unidades formadoras de colônias (UFCs) foram recolhidas de acordo com o método aleatório descrito por Ordoñez (1979). Estas UFCs foram pinçadas com palitos de madeira e semeadas, através do método de picadura, em placas de MRS-ágar $1,5 \%$, e incubadas por $12 \mathrm{~h}$ a $35^{\circ} \mathrm{C}$.

A Tabela 1 menciona os microrganismos utilizados como indicadores para as provas de atividade antimicrobiana das bactérias lácticas das linguiças artesanais de Santa Luzia, assim como a origem dos mesmos. Os microrganismos foram conservados liofilizados em leite desnatado a $10 \%$ e, após a sua recuperação, congelados a $-20^{\circ} \mathrm{C}$ em caldo nutritivo com $15 \%$ de glicerol.

Tabela 1 - Microrganismos indicadores utilizados nos testes de atividade antimicrobiana das cepas de bactérias lácticas isoladas das linguiças artesanais de Santa Luzia, MG

\begin{tabular}{ll}
\hline Microrganismo indicador & Origem \\
\hline Staphylococcus aureus & ATCC 25923 \\
Staphylococcus aureus & FRI 184 \\
Lactobacillus curvatus & CPB 2739 \\
Lactobacillus plantarum & CPB 1193 \\
Lactobacillus reuteri & CPB 20016 \\
Lactobacillus sake & CPB 2714 \\
Leuconostoc cremoris & CPB 1275 \\
Listeria monocytogenes Scott A & FVM \\
\hline
\end{tabular}

ATCC: American Type Culture Collection, Rockville, MD, EUA; CPB: Collection Project Bridge, Comunidade Econômica Européia; FRI: Food Research Institute, Madison, WI, EUA; FVM: Facultad Veterinaria de Madrid

A partir dos estoques de congelados, se tomavam alíquotas de $100 \mu \mathrm{l}$ de cada cultura dos microrganismos, inoculando-os em tubos de ensaio com $10 \mathrm{ml}$ de caldo $\mathrm{BHI}$ ou MRS que eram incubados a temperaturas de 32/ $37^{\circ} \mathrm{C}$ durante $12 \mathrm{~h}$ de acordo com a cepa utilizada. Esse procedimento recebeu a denominação de cultivo iniciador dos microrganismos indicadores.

Desses tubos, foram pipetados $100 \mu \mathrm{l}$ e transferidos para um tubo contendo $5 \mathrm{ml}$ de caldo BHI. Desse, pipetouse $1 \mathrm{ml}$ que foi transferido para outro tubo, contendo também $5 \mathrm{ml}$ de caldo BHI. Em seguida, $750 \mu \mathrm{l}$ do volume desse último tubo foram pipetados e transferidos para um tubo contendo $15 \mathrm{ml}$ de BHI-ágar $0,87 \%$. O seu conteúdo foi vertido cuidadosamente em uma placa de MRS-ágar contendo as UFCs de bactérias lácticas. As placas foram conduzidas à estufa por 24 a $48 \mathrm{~h}$. Após esse prazo, as placas foram observadas e aquelas UFCs de bactérias lácticas que promoveram algum tipo de inibição foram recuperadas. Essas UFCs foram submetidas a um cultivo iniciador e congeladas com $15 \%$ de glicerol. As cepas foram identificadas com a denominação DTEI seguida da numeração correspondente.

Para se avaliar a atividade inibidora indireta foram obtidos sobrenadantes livres de células das cepas selecionadas. Para isto, pipetaram-se $50 \mu$ do conteúdo dos tubos de congelamento, transferindo-os para tubos com $10 \mathrm{ml}$ de caldo MRS, incubados a $35^{\circ} \mathrm{C} / 12 \mathrm{~h}$. O conteúdo dos tubos foi centrifugado a 10.000 r.p.m ou 12.317 $x$ g, durante 10 min., a temperatura de $0^{\circ} \mathrm{C}$ (Santos, 1993). $\mathrm{O} \mathrm{pH}$ dos sobrenadantes foi medido e ajustado gotejando-se uma solução de hidróxido de sódio $(\mathrm{NaOH}) 1 \mathrm{~N}$ até que atingisse a faixa de 6,2 a 6,8. A microfiltração desses sobrenadantes foi realizada por meio de membranas filtrantes GS em éster de celulose com $0,22 \mu \mathrm{m}$ de poro e $25 \mathrm{~mm}$ de diâmetro, adaptadas a suportes plásticos próprios. Esse filtrado constituía o sobrenadante livre de células não concentrado, denominado " $\mathrm{s}$ ". Quinze ml deste filtrado foram transferidos para uma placa de Petri, congelados e posteriormente liofilizados. Os $5 \mathrm{~m}$ ! restantes foram mantidos em frasco de penicilina e armazenados a temperatura de $-20^{\circ} \mathrm{C}$. Para se obter os sobrenadantes concentrados (Sc), o " $s$ " liofilizado foi ressuspendido em uma solução tampão-fosfato, $4 \mathrm{mM}$, de pH 7,0, obtendose um Sc 20 vezes em relação ao original ("s"). Os Sc foram armazenados em frascos de penicilina e congelados e estocados no freezer $\left(-20^{\circ} \mathrm{C}\right)$.

A partir do cultivo iniciador dos indicadores, $100 \mu$ foram transferidos para um tubo contendo $5 \mathrm{ml}$ de caldo $\mathrm{BHI}$ ou MRS. Desse tubo pipetou-se $1 \mathrm{ml}$ que foi vertido para outro tubo contendo $5 \mathrm{ml}$ de caldo $\mathrm{BH}$ e desse foram passados $1,5 \mathrm{ml}$ para um tubo contendo $30 \mathrm{ml}$ de BHI-ágar $0,8 \%$ ou MRS-ágar $0,8 \%$, vertidos para placas descartáveis $(90 \times 15 \mathrm{~mm})$, incubadas em estufa de cultura a $37^{\circ} \mathrm{C} / 1 \mathrm{~h}$. Após este prazo, foram feitos furos no mesmo, utilizando-se canudos plásticos para refrigerante com $6 \mathrm{~mm}$ de diâmetro. Em cada furo no ágar, foram adicionados $50 \mu \mathrm{l}$ dos Sc das cepas a serem testadas. As placas foram levadas à geladeira, onde permaneceram por $2 \mathrm{~h} e$ incubadas sob condições ideais para o crescimento das cepas indicadoras durante 24 a $48 \mathrm{~h}$. Os halos de inibição foram observados e mensurados em mm (Santos, 1993).

Uma vez realizados todos os testes de difusão em ágar, 
seis cepas de bactérias lácticas isoladas foram escolhidas e testadas frente a outras bactérias lácticas e uma cepa de Listeria monocytogenes para avaliação do espectro de ação. As cepas de bactérias lácticas escolhidas (DTEI 094, DTEI 095 e DTEI 096) foram identificadas até gênero, pelo método de identificação rápida para lactobacilos descrito por Schillinger e Lücke (1987). Foram realizadas as seguintes provas: produção de gás, catalase, coloração de Gram, morfologia e crescimento a $15^{\circ} \mathrm{C}$.

\section{Resultdos e Discussão}

Das FCs crescidas no MRS-ágar, 48 foram repicadas, para cada amostra de linguiça, seguindo o método aleatório descrito por Ordoñez (1979), totalizando 336 UFCs. Todas estas bactérias foram examinadas para prova de Gram e atividade de catalase e classificadas como pertencentes ao grupo das bactérias lácticas. As bactérias lácticas isoladas das amostras apresentaram contagem global média variando entre $10^{7}$ e $10^{8} \mathrm{UFCs} / \mathrm{g}$. Este resultado foi bastante semelhante aos obtidos por outros pesquisadores que, após três ou quatro dias de fermentação, observaram uma contagem de $10^{8} \mathrm{UFCs} / \mathrm{g}$ que se manteve constante no período de maturação dos embutidos (Metaxopoulos et al., 1981; Samelis et al., 1994).

Conforme se pode observar na Tabela 2, 98 cepas das bactérias lácticas isoladas, apresentaram atividade antagonista direta frente a pelo menos uma das cepas de $S$. aureus, o que representa $29,2 \%$ das bactérias lácticas isoladas. Esses resultados não foram idênticos para as duas cepas usadas como indicadoras, o que significa que microrganismos distintos reagem diferentemente às substâncias produzidas pelas bactérias lácticas liberadas no meio extracelular (Schillinger \& Lücke, 1989; Daeschel et al., 1990). Dessa forma, o S. aureus ATCC 25923 mostrou-se menos resistente às bactérias lácticas selecionadas, uma vez que 58 UFCs $(17,3 \%)$ foram capazes de inibir o seu desenvolvimento no BHI-ágar, o que se observou através da formação de halos de inibição de crescimento ao redor das UFCs. Por outro lado, o S. aureusFRI 184 demonstrou resistência maior, de modo que somente 40 das 336 UFCs $(11,9 \%)$ foram capazes de inibi-lo.

Tabela 2 - Atividade inibitória direta das bactérias lácticas isoladas das linguiças artesanais de Santa Luzia frente às cepas indicadoras de Staphilococcus aureus

\begin{tabular}{lcc} 
Cepa indicadora & Número de UFCs & Percentual \\
\hline S. aureus ATCC 25923 & 58 & $17,3 \%$ \\
\hline S. aureus FRI 184 & 40 & $11,9 \%$ \\
Nenhuma atividade & 238 & $70,8 \%$ \\
Total & 336 & $100 \%$
\end{tabular}

Nenhuma cepa indicadora de $S$. aureus foi inibida pelos sobrenadantes livres de células das 98 cepas de bactérias lácticas isoladas que deram resultados positivos no teste de inibição direta, ou seja, os resultados da ativida- de inibitória indireta frente a esse microrganismo foram todos negativos.

As cepas DTEI 094, DTEI 095 e DTEI 096 foram positivas frente ao Leuconostoc cremoris CPB 1275 e ao Lactobacillus sake CPB 2714, microrganismos taxonomicamente relacionados, conforme mostra a Tabela 3 . Os halos de inibição produzidos pelas cepas DTEI 094, 095 e 096 tinham diâmetros aproximados de $17 \mathrm{~mm}$. Posteriormente, foram submetidas a provas de identificação do gênero bacteriano, tendo sido classificadas como Lactobacillus.

Durante a obtenção dos sobrenadantes livres de células utilizados nos testes de inibição indireta, isto é, testes que tentam detectar a presença de substâncias semelhantes a bacteriocinas produzidas pelas bactérias lácticas, algumas medidas são tomadas para se eliminar a possibilidade de que a inibição das cepas indicadoras tenha sido devida a outras substâncias. Dessa forma, o ajustamento do $\mathrm{pH}$ desses sobrenadantes, com solução de $\mathrm{NaOH} 1 \mathrm{~N}$, para uma faixa de 6,2 a 6,8, objetiva impedir a ação antagonista dos ácidos orgânicos (Piard e Desmazeaud, 1991; Schillinger et al., 1993; Holzapfel et al., 1995), enquanto o processo de liofilização, ao retirar os metabólitos do oxigênio e o peróxido de hidrogênio, descarta a possibilidade de a inibição ter sido provocada por essa's substâncias. Do mesmo modo, como os sobrenadantes tornaram-se isentos de células, após a microfiltração, a inibição não poderia ocorrer por competição direta.

Esses resultados sugerem que a inibição do $S$. aureus pelas bactérias lácticas, durante os testes de inibição direta, ocorreu sobretudo pela produção de ácidos orgânicos, formados durante a fermentação dos carboidratos presentes no meio e pela formação de peróxido de hidrogênio, podendo estar associados ao processo de competição pelos nutrientes, uma vez que, por terem sido eliminados, tais fatores não puderam exercer sua atividade antagonista. Vários trabalhos têm indicado que os ácidos orgânicos são realmente o principal fator inibidor das bactérias lácticas, ao instalarem um ambiente de elevada acidez no meio (Daeschel, 1989; Piard e Desmazeaud, 1991, 1992; González-Fandos et al., 1994; Holzapfel et al., 1995). As demais substâncias produzidas por elas como, por exemplo, as bacteriocinas, embora tenham grande capacidade antagonista, geralmente são produzidas em menores quantidades.

Não se pode afirmar que estes exemplares não produziram substâncias antagonistas semelhantes a bacteriocinas, uma vez que foram capazes de inibir indiretamente outras bactérias lácticas. No entanto, estas substâncias não possuem atividade antimicrobiana frente às cepas de $S$. aureus testadas no presente trabalho. Estes resultados indicam que os estafilococos possuem condições favoráveis para o seu crescimento e desenvolvimento nas linguiças artesanais de Santa Luzia, pois a microbiota presente neste embutido foi incapaz de liberar substância antimicrobiana extracelular no meio de cultura. 
Tabela 3 - Atividade antimicrobiana indireta das bactérias lácticas selecionadas frente a microrganismos indicadores diversos

\begin{tabular}{lcccccc}
\hline Microrganismo indicador & DTEI 094 & DTEI 095 & DTEI 096 & DTEl 097 & DTEI 098 & DTEI 099 \\
\hline Lactobacillus curvatus CPB 2739 & - & - & - & - & - & - \\
Lactobacillus plantarum CPB 1193 & - & - & - & - & - & - \\
Lactobacillus reuteri CPB 20016 & - & - & - & - & - & - \\
Lactobacillus sake CPB 2714 & + & + & + & - & - & - \\
Leuconostoc cremoris CPB 1275 & + & + & + & - & - & - \\
Listeria monocytogenes Scott A & - & - & - & - & - & - \\
Staphylococcus aureus ATCC 25923 & - & - & - & - & - & - \\
Staphylococcus aureus FRI 184 & - & - & - & - & - & - \\
\hline
\end{tabular}

\section{Abstract}

\section{Antimicrobial activity of lactic acid bacteria isolated from Brazilian fermented sausage}

The antimicrobial activity of 336 lactic acid bacteria isolated from dry fermented sausages was evaluated against several microorganisms. Ninety-eight strains showed direct antagonistic activities against Staphilococcus aureus at the primary tests, probably based on previous production of organic acids, hydrogen peroxid and oxygen metabolites or by competition. These microorganisms were checked by the well agar diffusion assay for their antagonistic activity against the same indicators and against other closely related bacteria. The inhibitory compound on one concentrated culture supernatant showed antagonistic effect against $S$. aureus or Listeria monocytogenes. Two strains of other lactic acid bacteria were inhibited by the supernatants cell-free from three selected strains. It appears that the lactobacilli are more sensitive than the staphyloococci. It also appears that the inhibitory spectra of the lactobacilli are varying significantly. All selected isolates with antagonistic activities were found to be Lactobacillus spp. The detection of lactic acid bacteria with inhibitorory properties from fermented sausages could be of interest in future applications in a meat system in order to control food spoilage and food-borne pathogenic bacteria such as $S$. aureus. Futher experiments and attempts to obtain antimicrobial sustances from lactic cultures producers should be carried out to achieve safer final products.

Key words: lactic acid bacteria; antimicrobial activity; fermented sausage

\section{Referências bibliográficas}

Bhunia AK, Johnson MC, Ray B et al. 1990. Antigenic property of pediocin AcH produced by Pediococcus acidilactici $\mathrm{H} . J$ Appl Bacteriol 69: 211-215.

Daeschel MA 1989. Antimicrobial substances from lactic acid bacteria for use as food preservatives. Food Technology 43(1): 164-166.

Daeschel MA, Mckenney MC, Mcdonald LC 1990. Bacteriocidal activity of Lactobacillus plantarum C-11. Food Microbiol 7(2): 91-98.
González-Fandos E, Otero A, Sierra M.et al. 1994. Effect of three commercial starters on growth of Staphylococcus aureus and enterotoxins (A-D) and thermonuclease production in broth. Intern J Food Microbiol 24(1/2): 321-327.

Holzapfel WH, Geisen R, Schillinger U 1995. Biological preservation of foods with reference to protective cultures, bacteriocins and food-grade enzymes. Inter J Food Microbiol 24(3): 343-362.

Jack RW, Tagg JR, Ray B 1995. Bacteriocins of Gram-positive bacteria. Microbiol Rev 59(2): 171-200.

Metaxopoulos J, Genigeorgis G, Fanelli MJ, Franti C, Cosma E 1981. Effect of starter cultures and chemical acidulation on staphylococcal growth in salami under commercial manufacturing conditions. Appl Environ Microbiol 42: 863871.

Ordoñez JA 1979. Random number sampling method for estimation of lactic acid bacteria. J Appl Bacteriol 46: 351 353.

Piard JC, Desmazeaud M 1991. Inhibiting factors produced by lactic acid bacteria. 1. Oxygen metabolites and catabolism end-products. Le Lait 71(5): 525-541.

Piard JC, Desmazeaud M 1992. Inhibiting factors produced by lactic acid bacteria. 2. Bacteriocins and other antibacterial substances. Le Lait 72(2): 113-142.

Samelis J, Stavropoulos S, Kakouri A et al. 1994. Quantification and characterization of microbial populations associated with naturally fermented greek dry salami. Food Microbiol 11(6): 447-460.

Santos WLM 1993. Aislamiento y caracterización parcial de una bacteriocina producida por Pediococcus sp. 347, de origem cárnico. Dissertação de Doutorado. Universidade Complutense de Madrid, Madrid, $294 \mathrm{pp}$.

Schillinger U, Lücke F-K 1989. Antibacterial activity of Lactobacillus sake isolated from meat. Appl Environ Microbiol 55(8): 1901-1906.

Schillinger U, Lücke F-K 1987. Identification of lactobacilli from meat and meat products. Food Microbiol 4: 199-208.

Schillinger U, Stiles ME, Holzapfel WH 1993. Bacteriocin production by Carnobacterium piscicola LV 61. Intern J Food Microbiol 20(3): 131-147.

Stamer JR 1979. The lactic acid bacteria: microbes of diversity. Food Technol 33(1): 60-65.

Tagg JR, Dajani AS, Wannamalker LW 1976. Bacteriocins of gram-positive bacteria. Bacteriol Rev 4O(3): 722-756.

Yamada EA, Beraquet NJ 1993. Embutido fermentado cozido. Coletânea do Instituto de Tecnologia de Alimentos/ITAL 23(1): 19-27. 